\title{
Numerical analysis and experimental validation on residual stress distribution of titanium matrix composite after shot peening treatment
}

Lechun Xie $^{\mathrm{a} *}$, Chengxi Wang ${ }^{\mathrm{a}}$, Liqiang Wang ${ }^{\mathrm{a}}$, Zhou Wang ${ }^{\mathrm{b}}{ }^{*}$, Chuanhai Jiang ${ }^{\mathrm{a}}$, Weijie $\mathrm{Lu}^{\mathrm{a}}$, Vincent $\mathrm{Ji}^{\mathrm{c}}$

${ }^{a}$ State Key Laboratory of Metal Matrix Composites, School of Materials Science and Engineering, Shanghai Jiao Tong University, No. 800 Dongchuan Road, Shanghai 200240, P.R. China

${ }^{\mathrm{b}}$ School of Automotive Engineering, Wuhan University of Technology, 122 Luoshi Road, Wuhan, Hubei 430070, P.R. China

${ }^{\text {c }}$ LEMHE/ICMMO, UMR 8182, Université Paris-Sud 11, 91405 Orsay France

* Corresponding author: lechunxie@yahoo.com; wangzhou@whut.edu.cn 


\section{Abstract}

The residual stress distribution introduced by shot peening (SP) in the deformed surface layer of titanium matrix composite $(\mathrm{TiB}+\mathrm{TiC}) / \mathrm{Ti}-6 \mathrm{Al}-4 \mathrm{~V}$ was investigated via three-dimensional (3D) finite element dynamic simulation and experimental validation. The program of ANSYS/LS-DYNA was utilized in the 3D finite element dynamic analysis of SP process, and the 3D homogeneous and inhomogeneous models were set up. The results showed that the compressive residual stresses (CRS) were introduced in the matrix, but the tensile residual stresses appeared in the reinforcements. The maximum CRS and tensile residual stress were -1511 and +1155 MPa respectively, which revealed the higher yield strength of reinforcements. This type of stress distribution revealed the effect of reinforcements, keeping the adverse tensile stresses in the reinforcements and retarding the damage to the matrix during deformation. In terms of experiments, after SP, the residual stresses along the depth from the surface were measured using X-ray diffraction (XRD) method. The experimental results indicated that the CRS formed in the surface layer and the maximum appeared on the subsurface. The range of residual stresses found in experiments supported the simulated results, which verified the validity of $3 \mathrm{D}$ finite element dynamic analysis.

Key words: Titanium matrix composite; Finite element dynamic analysis; Residual stress; Reinforcement; Shot peening; X-ray diffraction. 


\section{Introduction}

Shot peening (SP) can considerably improve fatigue strength and fatigue lives of cyclically loaded metallic components by inducing compressive residual stresses (CRS) and work hardening into the surface region (Schulze, 2003). Magnitude, distribution and depth of the CRS are mainly influenced by the material condition and the parameters of SP process. SP is a complex process and there are a significant number of parameters involved, which need to be controlled and regulated to produce an optimum CRS distribution. During the practical application of SP in industry, empirical knowledge should be accumulated for determining the appropriate processing parameters, which usually requires money and is time-consuming. In order to minimize these trials and obtain the suitable SP parameters as quickly and efficiently as possible, the simulation of the SP process is introduced, which can increase understanding of the SP process with the purposes of investigation, illuminating and predicting the relationship between the influencing factors and results.

Simulation of the SP process has been developed for more than four decades. Some research papers have shown that finite element methods for simulation is useful for predicting residual stress distribution after SP (Kim et al., 2011; Benedetti et al., 2010; Kim et al., 2010; Prasannavenkatesan et al., 2009). The simulation of SP process via finite element methods can be classified into two-dimensional (2D) and three-dimensional (3D) models. 2D SP models are usually utilized to simulate a single impact on a cylindrical or semi-infinite target body, and the verification of model 
accuracy is commonly realized by the comparison of the simulated residual stresses with the results measured by X-ray diffraction (XRD) and neutron diffraction (Ould et al., 2006; Baragetti et al., 2000; Boyce et al., 2001; Evans, 2002). However, direct comparison of the residual stress distribution along the symmetry axis of a $2 \mathrm{D}$ model with the experimental measurements on a peened component is questionable because the measurement area is different from the impact area in the 2D model. Stress measurement techniques like $\mathrm{XRD}$, neutron diffraction or hole drilling can provide macroscopic stress values, and the measurement area is larger than the diameter of the dimple used in 2D model. Furthermore, during multiple SP processes, the coverage rate, a very important parameter, can't be taken into account in $2 \mathrm{D}$ models, which led to the introduction and popular application of 3D models.

3D SP models are being used in practical work more and more because they can take into account the effect of coverage rate. Consequently, 3D SP models have become the main choice in recent years, especially 3D models with dynamic analysis. In the overview of $\mathrm{SP}$ simulation, some $3 \mathrm{D}$ models are proposed with different descriptions, numbers of shot balls, types of analysis, kinds of material models, and so on (Levers and Prior, 1998; Meguid et al., 1999; Majzoobi et al., 2005; Frija et al., 2006; Wang et al., 2008; Hong et al., 2008; Kim et al., 2012; Meo and Vignievic, 2003). Based on above 3D models, there are many studies on SP simulation regarding homogeneous materials, little investigation involves 3D inhomogeneous inclusions while setting up models. Even though some researchers have set up 3D inhomogeneous models of metal matrix composites by other methods (Bohm, et al., 
2001; Bohm et al., 2002; Han et al., 2001; Duschlbauer et al., 2006; Borbely et al., 2001), there are few studies focusing on the SP process.

As an important metal matrix composite, titanium matrix composite has wide application prospects in the aerospace, automobile and other industries because of good properties such as high specific strength, good ductility, and excellent fatigue properties etc. (Tjong and Ma, 2000; Ranganath, 1997). Experimental investigation concerning the residual stress distribution of titanium matrix composite after SP has been carried out in previous works using the XRD method (Xie et al., 2011a; Xie et al., 2011b). However, the tested residual stresses just show the average residual stresses of the matrix and reinforcements, since the irradiation area of X-ray is larger than the dimensions of the reinforcements. It is very hard to measure the residual stress distribution in and around the reinforcements directly via experimental methods, which can depend on the simulation. Thus, in this work, 3D finite element dynamic analysis of multiple shot impacting is carried out on titanium matrix composite $(\mathrm{TiB}+\mathrm{TiC}) / \mathrm{Ti}-6 \mathrm{Al}-4 \mathrm{~V}(\mathrm{TiB}: \mathrm{TiC}=1: 1(\mathrm{vol} \%))$, and the SP target component involves the matrix Ti-6Al-4V and the inhomogeneous reinforcements $\mathrm{TiB}$ and $\mathrm{TiC}$. The program of ANSYS/LS-DYNA (ANSYS Company, 2010) is utilized to simulate the SP process. A parametric study is conducted using this 3D dynamic model to investigate the influences of shot velocity and coverage rate on the residual stress distribution after SP. The residual stresses in and around reinforcements can be obtained and discussed in detail. Moreover, the experimental results using XRD method are compared with the simulated results. 


\section{Models and Experiments}

\section{1. Homogeneous SP model}

ANSYS/LS-DYNA is utilized for the 3D finite element dynamic analysis of the shot impacting on the surface. The process of SP causes a plastic deformation on the matrix, so Cowper-Symonds model (Symonds, 1965; Johnson and Cook, 1983; Jones, 1997; Hallquist, 2006) in ANSYS is chosen to use in the 3D finite element dynamic analysis. Cowper-Symonds model is a piecewise linear plasticity model, and the yield stress can be obtained via the strain rate, which is shown in Eq. (1) (He et al., 2013).

$$
\sigma_{y}\left(\varepsilon_{\text {eff }}^{p}, \dot{\varepsilon}_{\text {eff }}^{p}\right)=\sigma_{y}\left(\varepsilon_{\text {eff }}^{p}\right)\left[1+\left(\frac{\dot{\varepsilon}_{\text {eff }}^{p}}{C}\right)^{\frac{1}{p}}\right]
$$

Where $\dot{\varepsilon}$ represents the effective strain rate, $P$ and $C$ are the parameters for strain rate, and $\sigma_{y}\left(\varepsilon_{\text {eff }}^{p}\right)$ is the original yield stress. Because of the existence of reinforcements and in order to mainly analyze the influences of reinforcements on the residual stress distribution of the matrix, the strain-stress curves with a single strain rate $\left(10^{-3} \mathrm{~s}^{-1}\right)$ of the matrix and composite are adopted in the simulation process. It was pointed out that dynamic stress-strain curves become flatter with an increase in strain-rate, with reduced material strain hardening (Symonds, 1965). Therefore, considering the variation of strain rates, according to Eq. (1) and the references (Jones, 1983; Aljawi, 2004), the parameters $C$ and $P$ are set as $C=1300$ and $P=5$.

Before analyzing the model of titanium matrix composite (TiB+TiC)/Ti-6Al-4V, the 3D model of homogeneous matrix Ti-6Al-4V should be set up, which is shown in Fig. 1. The dimensions of the peened target are $12 R \times 6 R \times 2.1 \mathrm{~mm}^{3}$, in which $R$ is the average radius of shot balls. In the impact area, a mesh refinement at the near surface 
layer is used because of intensive impacting, and the depth of the mesh is $0.02 \mathrm{~mm}$. The mesh number reaches 120,000 in total, and the SOLID164 dynamic analysis display unit is chosen for meshing unit. Because the impact process of SP shows symmetry, this 3D model is set up in symmetry and is half of the actual size. In order to avoid the influence of reflected stress wave within the target on the distribution of residual stress during the process of impacting, non-reflective boundary conditions are implemented on the bottom and flanks of the target.

During the simulation process, the shot media is the case steel ball, and to shorten the simulation time, all freedom degrees of shot balls are coupled to the rigid body center of mass, meanwhile, the corresponding mechanical parameters are given to the rigid body center to describe the dynamic characteristics. Because the hardness of the matrix is smaller than that of the case steel balls, the deformability of the shot balls is very weak, which hardly affects the results of residual stress distribution. Thus, the shot balls are assumed to be rigid. About the reinforcements of $\mathrm{TiB}$ and $\mathrm{TiC}$ particles, the Young's modulus is much greater than that of Ti-6Al-4V, and the hardness of the reinforcements are comparative equal to or greater than the hard ceramic, thus, the reinforcements can be considered also as rigid bodies, and there is hardly having any plastic deformation during the process of SP. However, after SP treatments, because of the constraint of the matrix around the reinforcements, residual stresses still exist in the reinforcements in order to keep a balanced stress distribution, which is different from the situation of the shot balls. Consequently, only the elastic properties of reinforcements are provided in this work. In addition, the coverage rate 
is very important to the distribution of residual stresses. Thus, approximate the practical situation, four impacts with shot balls are carried out in this 3D model. The detailed description of the coverage rate is shown in Fig. 2. With a single impact, the coverage rate is about $25 \%$, and after four impacts, the coverage rate approaches $100 \%$. To increasing coverage rate to $200 \%$, eight impacts should be carried out.

\subsection{Experiments}

Before simulation, the typical mechanical parameters of shot balls, targets and reinforcements are shown in Table 1. The elastic-plastic properties of targets were obtained from the tensile tests. The tensile tests were performed using a Zwick T1-FR020TN test machine in air, and the initial strain rate was $10^{-3} \mathrm{~s}^{-1}$. The stress-strain curves are shown in Fig. 3, which have been implemented in the simulation process. The schematic diagram of SP process is shown in Fig. 1. The intensity of SP is measured using the arc height of the Almen specimen (A type), which is influenced by the jet pressure of nozzle, SP time and the average diameter of shot balls. In this study, SP treatment was performed using an air blast machine (Carthing Machinery Company, Shanghai, China). The SP intensities were: 0.15, 0.30 and $0.45 \mathrm{mmA}$. The diameter of peening nozzle was $15 \mathrm{~mm}$, and the distance between nozzle and samples was $100 \mathrm{~mm}$. The shot media was cast steel balls with a hardness of $610 \mathrm{HV}$ and average diameter of $0.6 \mathrm{~mm}$. For obtaining an even stress field on the surface of materials, the coverage rate of SP process was $100 \%$.

Residual stresses were measured using an X-ray stress analyzer (LXRD, Proto, 
Canada) with $\mathrm{Cu}-\mathrm{Ka}$ radiation under $30 \mathrm{kV} / 25 \mathrm{~mA}$ and Ni filter. The diffraction peak of $\mathrm{Ti}$ (213) was detected in the measurements and then the residual stresses were determined according to the $\sin ^{2} \psi$ method (Withers and Bhadeshia, 2001), with the range of tilting angles from $0^{\circ}$ to $45^{\circ}$. To obtaining the stress distribution deeper inside the material, the thin top surface was removed layer by layer via chemical etching with a solution of distilled water, nitric acid, and hydrofluoric acid in the proportion of 31:12:7. The estimated X-ray penetration depth for each measurement was about 5-10 $\mu \mathrm{m}$ for titanium alloys. The chemical etching rate could be determined from the etching time and the concentration of mixed solution. According to our experiments, the chemical etching rate of Ti-6Al-4V was about $10-13 \mu \mathrm{m} / \mathrm{min}$. The values of depth could be determined by the micrometer, and the minimum interval depth between two layers was about $15 \mu \mathrm{m}$, which was larger than the X-ray penetration depth. So the layers removed by chemical etching were thick enough compared to the X-ray penetration depth to ensure no overlapping data on residual stress profiles.

While using chemical etching, the structure of deep surface layers is not be destroyed, and the relaxation of residual stresses is very weak. Moreover, the residual stresses obtained by X-ray Stress Analyzer are planar stresses. Therefore, the relaxation of residual stresses resulting from chemical etching can be ignored. In addition, the diffraction peak of $\mathrm{Ti}(213)$ is detected in the measurements, and there is no deviation of the location of the diffraction peak after chemical etching, so the same test parameters are utilized to measure the residual stresses in depth, and there is no 
need to do a correction for the residual stress profiles.

In order to set up the 3D SP model for inhomogeneous materials, the microstructure of reinforcements was observed by scanning electron microscopes (SEM, Hitachi S-3400N, Japan) with a voltage of $15 \mathrm{kV}$, and a current of $70 \mu \mathrm{A}$. Standard metallographic grinding and polishing procedures were used before SEM observation. The surface of the sample was ground using different abrasive papers $(400+600+800$ grit $)$ over a short time, and polished using $9 \mu \mathrm{m}$ and $3 \mu \mathrm{m}$ diamond suspensions, and then a $0.05 \mu \mathrm{m}$ aluminum oxide suspension in that order. In order to acquire clear morphology of reinforcements, the sample surface was etched using Kroll's solution (HF: $\mathrm{HNO}_{3}: \mathrm{H}_{2} \mathrm{O}=3: 5: 100$ (vol)) for $2-6 \mathrm{~s}$ after polishing. All experiments were performed at room temperature.

\section{Results and discussion}

\section{1. Simulated results from homogeneous SP model}

The velocity of the shot ball is a crucial factor for residual stress distribution. In order to simulate the practical process of SP better, the actual velocity of the shot ball is estimated by the semi-experiential formula introduced by Dr. Klemenz (Klemenz, 2009), which is shown below in Eq. (2).

$$
v=\frac{16.35 \times p}{1.53 \times m+p}+\frac{29.50 \times p}{0.598 \times d+p}+4.83 \times p
$$

Where, $p, m, d$ represent the jet pressure (bar), the flux of shot balls $(\mathrm{kg} / \mathrm{min})$, and the diameter of shot balls $(\mathrm{mm})$, respectively. In the experiment, the value of $m$ is 0.5 $\mathrm{kg} / \mathrm{min}$. The parameters with different SP intensities are listed as below: (1) 0.15 
mmA (SP intensity), 4 bar (air pressure), $0.5 \mathrm{~min}$ (SP time); (2) $0.3 \mathrm{mmA}, 10$ bar, 0.5 min. The average diameter of the shot balls is $0.6 \mathrm{~mm}$. According to above conditions, the approximate velocities of shot balls can be estimated as 57 and $92 \mathrm{~m} / \mathrm{s}$, corresponding to the SP intensities of 0.15 and $0.3 \mathrm{mmA}$ respectively. Consequently, the shot velocities of 50 and $100 \mathrm{~m} / \mathrm{s}$ are considered in this simulation.

The effect of the coverage rate on the residual stress distribution is also very important. In general, the strengthening effect of SP on surface can be fully realized only up to a certain SP intensity and a coverage rate. Low coverage rate $(<75 \%)$ usually leads to the residual tensile stress on surface, which is extremely unfavorable to the surface mechanical properties, so in the industry, each SP coverage rate requires at least $100 \%$. In actual application, the SP coverage rate generally is greater than $100 \%$, and reaches $200 \%$ or more. But it is not reasonable that much higher coverage rate would improve the surface mechanical properties more, since excessive coverage rate may lead to stress concentration or surface microcracks, which are disadvantageous to the surface mechanical properties. Thus, an appropriate SP coverage rate should be set. The simulated results of residual stress distribution of Ti-6Al-4V (matrix) under different coverage rates of 100\%, 200\% and 300\% are shown in Fig. 4(a), the shot's average velocity is $50 \mathrm{~m} / \mathrm{s}$, and the average radius of the shot balls is $0.3 \mathrm{~mm}$. The in-depth residual stress profiles are estimated by averaging the nodal stresses over the shot peened area. Other parameters maintain constants. As can be seen from the figure, with the increase of coverage rate, the CRS and the depth of the strain layer are improved. Comparing the results under the coverage rate of $200 \%$ 
and $300 \%$, it can be found that the increment of surface residual stress does not increase proportional to the coverage rate, since the surface of almost all area is covered by craters and the stress field reaches saturation.

During the process of simulation, the initial velocity of shot balls represents the SP intensity, the larger of velocity, the higher SP intensity. Fig. 4(b) indicates the residual stress distribution in depth while the initial velocity increases to $100 \mathrm{~m} / \mathrm{s}$. Compared to Fig. 4(a), the variation trends are similar, but with the increase of velocity, the CRS significantly increases and the maximum value reaches $-560 \mathrm{MPa}$ in the subsurface. When the velocity of the shot ball is set as $100 \mathrm{~m} / \mathrm{s}$, the maximum residual stress no longer increases even after the SP coverage rate equals or exceeds 200\%. This result indicates that once the impact effect on material reaches a certain level, some certain features of the residual stress field vary only slightly, and finally these values can be considered as the saturation values.

The simulated pictures about residual stress distribution under different coverage rates are shown in Fig. 5, when the initial velocity of $100 \mathrm{~m} / \mathrm{s}$ and the radius of 0.3 $\mathrm{mm}$ are selected. It can be found that, with the improvement of coverage rate, the number of craters on the surface is obviously increased, and the uniformity of surface residual stresses is improved greatly. Meanwhile, viewed from the cross section, the uniformity of residual stress distribution on subsurface is also improved, and a small amount of the tensile stress in the deep surface decreases gradually and eventually disappears with the increase of coverage rate. 


\section{2. Simulated results from inhomogeneous SP model}

\subsubsection{Inhomogeneous SP model}

Based on the simulated results from the homogeneous model, the inhomogeneous SP model containing the reinforcements is set up in this section, and the residual stress distribution in and around the reinforcements is obtained and analyzed. In this model, the initial velocity of $100 \mathrm{~m} / \mathrm{s}$, the radius of $0.3 \mathrm{~mm}$ and the coverage rate of $200 \%$ are chosen as the initial parameters. The 3D SP model for inhomogeneous materials is based on the microstructure of the reinforcements, which in $8 \%(\mathrm{TiB}+\mathrm{TiC}) / \mathrm{Ti}-6 \mathrm{Al}-4 \mathrm{~V}$ are observed by SEM and shown in Fig. 6, indicating that the reinforcements are distributed uniformly in the composite. The reinforcements like short sticks are $\mathrm{TiB}$, while the equiaxed or near equiaxed particles are $\mathrm{TiC}$ reinforcements.

The 3D SP model for inhomogeneous materials is shown in Fig. 7 based on the microstructure observation of reinforcements. In the figure, the shot ball, the matrix and the reinforcements are labeled. The parts with disjunction distribution represent the reinforcements $\mathrm{TiB}$ and $\mathrm{TiC}$, and the $1 / 4$ spherical object is the shot ball. Because the mehanical parameters of these two kinds reinforcements are similar, one kind of mesh is used in this model for simplifing the calculation and shortening the processing time. Moreover, the whole mesh number reaches 320,000 and the simulation process takes about one week. The quite fine mesh is introduced in the relatively large area of plastic deformation, actually in the directly impact area. In this 3D inhomogeneous SP model, the volume percentage of reinforcement is chosen as $8 \%$ 
according to the material. The $1 / 4$ symmetrical model is set up and the non-reflecting boundary conditions on the flanks of model are applied. To avoid the effect of stress wave, the symmetric boundary conditions are also applied on the symmetry plane.

\subsubsection{Residual stress distribution obtained from inhomogeneous SP model}

The residual stress distribution of composite material on the plastic deformation zone is shown in Fig. 8, and the direction of distribution is along $x$ direction $\left(\sigma_{x x}\right)$. From the residual stress contours, it is indicated that the plastic deformation occurs on the surface layer after SP, and both the compressive and tensile residual stresses are introduced. The maximum CRS and tensile residual stress are $-1511 \mathrm{MPa}$ and +1155 $\mathrm{MPa}$ respectively. Moreover, the residual stresses in the matrix are compressive stresses, but tensile residual stresses appear in the reinforcements, which indicate that the reinforcements withstand the tensile stresses after SP, and this type of stress distribution reveals the higher yield strength of reinforcements. This type of stress distribution indicates the effect of reinforcements, keeping the balance of residual stress distribution, retaining the adverse tensile stresses in the reinforcements and retarding the damage to the matrix. Furthermore, the different distributions of residual stresses between the matrix and reinforcements are caused by the different mechanical properties, which agree with the desired results after SP treatments.

In the process of SP, the deformation in the matrix and reinforcements take place after impacting. Since the yield strength and Young's modulus of reinforcement are much higher than the matrix's, the plastic deformation of the matrix is more severe 
than that of reinforcement under the same SP intensity. Meanwhile, because of the constraint of the matrix around the reinforcements, the residual tensile stresses remain in the reinforcements in order to keep balance on stress distribution. The tensile stresses in reinforcement are much lower than the strength of reinforcement, it is reasonable to believe that these tensile stresses have no detrimental influences on the fatigue properties of shot peened composites. In addition, it can be seen that the CRS in the matrix increases first and then decreases with increasing depth, and the maximum appears in the subsurface. In order to verify the simulated results obtained by $3 \mathrm{D}$ finite element dynamic analysis, the experimental investigation on the residual stress distribution of Ti-6Al-4V and $8 \%$ (TiB+TiC)/Ti-6Al-4V after SP are implemented via the XRD method.

\subsection{Experimental results and discussion}

\subsubsection{Residual stress distribution of Ti-6Al-4V}

The CRS distribution of Ti-6Al-4V under three different SP intensities is shown in Fig. 9. The residual stresses are compressive stresses, and the values increase to maximum and then decrease, which support the simulated results of the homogeneous SP model. When the SP intensity increases from 0.15 to $0.45 \mathrm{mmA}$, the CRS of surface is enhanced from -517 to $-605 \mathrm{MPa}$, an improvement of $17 \%$. The maximum CRS varies from -684 to $-794 \mathrm{MPa}$, and the increase is about $16 \%$. The maximum CRS appear at 50, 50 and $75 \mu \mathrm{m}$, corresponding to the intensity of $0.15,0.30$ and 0.45 $\mathrm{mmA}$, respectively. The depths of surface deformation layers are 275, 325 and 400 
$\mu \mathrm{m}$, which shows that the deformation depth increases gradually with the increment of SP intensity. It is mainly due to the improved impacting of shot balls after increasing SP intensity, which can result in the more severe plastic deformation on the surface, and the larger CRS, the deeper deformation layer. Comparing the results by simulation and experiments, it reveals that the variation trends of residual stress by experiments are similar with the results from simulation, and the maximum CRS by simulation is close to the experimental results, which indicate that the simulated results by $3 \mathrm{D}$ finite element dynamic analysis are valid.

\subsubsection{Residual stress distribution of $8 \%(\mathrm{TiB}+\mathrm{TiC}) / \mathrm{Ti}-6 \mathrm{Al}-4 \mathrm{~V}$}

Fig. 10 shows the experimental results of residual stress distribution on $8 \%$ $(\mathrm{TiB}+\mathrm{TiC}) / \mathrm{Ti}-6 \mathrm{Al}-4 \mathrm{~V}$ under different SP intensities. From the figure, the variation trends of residual stresses are similar to Fig. 9, and the maximum CRS all appear at 25 $\mu \mathrm{m}$, which are shallower than the matrix's under the same SP intensity. The depths of deformation layer are 200, 250 and $300 \mu \mathrm{m}$ corresponding to $0.15,0.30$ and 0.45 mmA, which are also shallower than the matrix's. The results different from the matrix's are caused by the presence of the reinforcements' resistance to the deformation of the surface. When other conditions are invariable, SP intensity has a direct relation to the impact velocity of shot balls. The larger impact velocity, the higher the impact's kinetic energy, and the depth of deformation layer increases. At the same depth, the higher SP intensity, the values of CRS are bigger. Consequently, both the CRS and the depth of surface deformation layer are strongly influenced by 
the impact velocity of shot balls.

In addition, the CRS of surface is enhanced from -545 to $-724 \mathrm{MPa}$, and the maximum CRS varies from -655 to $-819 \mathrm{MPa}$. Comparing the results from simulation and experiments, the ranges of residual stresses measured via experiments are in agreement with the simulated results found through 3D finite element dynamic analysis shown in Fig. 8. The tested residual stresses show the average values of the matrix and reinforcements because the irradiation area of X-ray is larger than the dimension of reinforcement, certainly, the differences still exist between the simulation and experiments. Based on all results and discussion, it can be found that using 3D finite element dynamic analysis to simulate the residual stress distribution of the titanium matrix composite after SP is valid, especially because, it is an effective method to obtain the residual stress distribution in and around the reinforcements.

\section{Conclusion}

The 3D finite element dynamic simulation and the experimental validation on the residual stress distribution of surface deformation layer of (TiB+TiC)/Ti-6Al-4V after SP were investigated. In the simulation, the program of ANSYS/LS-DYNA was utilized for the 3D finite element dynamic analysis, and both the 3D homogeneous and inhomogeneous models were set up. The results revealed that the compressive and tensile residual stresses were introduced. The maximum CRS and tensile residual stress were -1511 and $+1155 \mathrm{MPa}$ respectively. The residual stresses in the matrix were compressive stresses, but the tensile residual stresses generated in the 
reinforcements, which revealed the higher yield strength of reinforcements. This type of stress distribution revealed the effect of reinforcements, keeping the adverse tensile stresses in the reinforcements and retarding the damage to the matrix. The experimental investigation on the residual stress distribution of $8 \%$ (TiB+TiC)/Ti-6Al-4V after SP was carried out via the XRD method. The CRS of surface was enhanced from -545 to $-724 \mathrm{MPa}$, and the maximum CRS varied from -655 to -819 MPa. Comparing the results obtained from the simulation and experiments, the ranges of residual stress distribution in experiments supported the simulated results found by 3D finite element dynamic analysis. Based on all results and discussion, it can be shown that using 3D finite element dynamic analysis to simulate the residual stress distribution of titanium matrix composite is valid, especially for the stress distribution in and around the reinforcements.

\section{Acknowledgment}

This work is supported by the projects of National Science Foundation of China (Grant No: 51302168), the 973 Program (Grant No: 2014CB046701), Jiangxi Foreign Cooperation Program (Grant No.: 20144BDH80004), and Shanghai Pujiang Program (Grant No: 15PJD017). The financial support of the National Natural Science Foundation of China (No. 51405356) and the Research Fund for the Doctoral Program of Higher Education of China (No. 20130143120015) are appreciated. The authors gratefully acknowledge Mr. Timothy Ethington and Mr. Landon Ostler for their assistance on improving the language. 


\section{References}

Aljawi, A.A.N., 2004. Plastic Deformation of Thin Plates Subjected to Quasi-Static and Dynamic Loadings. J. Eng. Res. 1, 59-74.

ANSYS Company, 2010. ANSYS/LS-DYNA Users' Guide.

Baragetti, S., Guagliano, M., Vergani, L., 2000. A numerical procedure for shot peening optimization by means of non-dimensional factors. Int. J. Mater. Prod. Tech. 15, 91-103.

Benedetti, M., Fontanari, V., Monelli, B.D., 2010. Numerical simulation of residual stress relaxation in shot peened high-strength aluminum alloys under reverse bending fatigue. J. Eng. Mater. Technol. 132, 11012.

Bohm, H.J., Han, W., 2001. Comparisons between three-dimensional and two-dimensional multi-particle unit cell models for particle reinforced metal matrix composites. Modelling Simul. Mater. Sci. Eng. 9, 47-65.

Bohm, H.J., Eckschlager, A., Han, W., 2002. Multi-inclusion unit cell models for metal matrix composites with randomly oriented discontinuous reinforcements. Comp. Mater. Sci. 25, 42-53.

Borbely, A., Biermann, H., Hartmann, O., 2001. FE investigation of the effect of particle distribution on the uniaxial stress-strain behaviour of particulate reinforced metal-matrix composites. Mater. Sci. Eng. A 313, 34-45.

Boyce, L.B., Chen, X., Hutchinson, J.W., Ritchie, O.R., 2001. The residual stress state due to a spherical hard-body impact. Mech. Mater. 33, 441-454.

Duschlbauer, D., Bohm, H.J., Pettermann, H.E., 2006. Computational Simulation of 
Composites Reinforced by Planar Random Fibers: Homogenization and Localization by Unit Cell and Mean Field Approaches. J. Compos. Mater. 40, 2217-2234.

Evans, R., 2002. Shot peening process: modeling, verification, and optimization. Mater. Sci. Tech. 18, 831-839.

Frija, M., Hassine, T., Fathallah, R., Bouraoui, C., Dogui, A., 2006. Finite element modelling of shot peening process: Prediction of the compressive residual stresses, the plastic deformations and the surface integrity. Mater. Sci. Eng. A 426, 173-180.

Hallquist, J.O., 2006. LS-DYNA theoretical manual. Livermore Software Technology Corporation.

Han, W., Eckschlager, A., Bohm, H.J., 2001. The effects of three-dimensional multi-particle arrangements on the mechanical behavior and damage initiation of particle-reinforced MMCs. Compos. Sci. Technol. 61, 1581-1590.

He, X., Xing, B., Zeng, K., Gu, F., Ball, A., 2013. Numerical and experimental investigations of self-piercing riveting. Int. J. Adv. Manuf. Tech., 69, 715-721.

Hong, T., Ooi, J.Y., Shaw, B., 2008. A numerical simulation to relate the shot peening parameters to the induced residual stresses. Eng. Fail. Anal. 15, 1097-1110.

Johnson, G.R., Cook, W.H., 1983. A Constitutive Model and Data for Metals Subjected to Large Strains, High Strain Rates and High Temperatures. Presented at the Seventh International Symposium on Ballistics, Hague, Netherlands.

Jones, N., 1983. Structural Aspect of Ship collisions. In Structural Crashworthiness, Chapter 11 (Edited by N. Jones and Wierzbicki), Butterworth, 308-337. 
Jones, N., 1997. Structural Impact. Cambridge University Press.

Kim, T., Lee, J.H., Lee, H., Cheong, S., 2010. An area-average approach to peening residual stress under multi-impacts using a three-dimensional symmetry-cell finite element model with plastic shots. Mater. Design 31, 50-59.

Kim, T., Lee, H., Hyun, H.C., Jung, S., 2011. A simple but effective FE model with plastic shot for evaluation of peening residual stress and its experimental validation. Mater. Sci. Eng. A 528, 5945-5954.

Kim, T., Lee, H., Jung, S., Lee, J.H., 2012. A 3D FE model with plastic shot for evaluation of equi-biaxial peening residual stress due to multi-impacts. Surf. Coat. Tech. 206, 3125-3136.

Klemenz, M., 2009. Anwendung der Simulation der Randschichtausbildung beim Kugelstrahlen auf die Abschätzung der Schwingfestigkeit gekerbter Bauteile. PhD-thesis, Universität Karlsruhe, ISBN 978-3-8322-8720-7, Shaker, Aachen.

Levers, A., Prior, A., 1998. Finite element analysis of shot peening. J. Mater. Process. Tech. 80-81, 304-308.

Majzoobi, G.H., Azizi, R., Nia, A.A., 2005. A three-dimensional simulation of shot peening process using multiple shot impacts. J. Mater. Process. Tech. 164-165, $1226-1234$

Meguid, S.A., Shagal, G., Stranart, J.C., Daly, J., 1999. Three-dimensional dynamic Finite element analysis of shot-peening induced residual stresses. Finite Elem. Anal. Design 31, 179-191.

Meo, M., Vignievic, R., 2003. Finite element analysis of residual stress induced by 
shot peening process. Adv. Eng. Soft. 34, 569-575.

Ould, C., Rouhaud, E., Francois, M., Chaboche, J.L., 2006. A kinematic hardening finite elements model to evaluate resiudal stressesin shot-peened parts, local measurements by x-ray diffraction. Mater. Sci. Forum. 524-525, 161-166.

Prasannavenkatesan, R., Zhang, J., McDowell, D.L., Olson, G.B., Jou, H.J., 2009. 3D modeling of subsurface fatigue crack nucleation potency of primary inclusions in heat treated and shot peened martensitic gear steels. Int. J. Fatigue 31, 1176-1189.

Ranganath, S., 1997. A Review of Particulate Reinforced Titanium Composites. J. Mater. Sci. 32, 1-16.

Schulze, V., 2003. Characteristics of surface layers produced by shot peening. ICSP-8 in Garmisch-Partenkirchen, Wiley-VCH, Germany.

Symonds, P.S., 1965. Viscoplastic Behavior in response of Structures to Dynamic Loading. Behavior of Materials Under Dynamic Loading (Edited by N.J. Huffington), New York, 106-124.

Tjong, S.C., Ma, Z.Y., 2000. Microstructural and mechanical characteristics of in situ metal matrix composites. Mater. Sci. Eng. R 29, 49-113.

Wang, T., Platts, M.J., Wu, J., 2008. The optimisation of shot peen forming processes. J. Mater. Process. Tech. 206, 78-82.

Withers, P., Bhadeshia, H., 2001. Residual Stress Part 1 - Measurement Techniques, Mater. Sci. Tech. 17, 355-365.

Xie, L., Jiang, C., Lu, W., Zhan, K., Chen, Y., 2011. Investigation on the residual stress and microstructure of $(\mathrm{TiB}+\mathrm{TiC}) / \mathrm{Ti}-6 \mathrm{Al}-4 \mathrm{~V}$ composite after shot peening. 
Mater. Sci. Eng. A 528, 3423-3427.

Xie, L., Jiang, C., Lu, W., Feng, Q., Wu, X., 2011. Investigation on the surface layer characteristics of shot peened titanium matrix composite utilizing X-ray diffraction. Surf. Coat. Tech. 206, 511-516. 


\section{Figure captions}

Fig. 1 3D SP model for homogeneous materials

Fig. 2 Coverage rates of SP with different impacts

Fig. 3 Stress-strain curves of the matrix and the composite

Fig. 4 Computed residual stress distribution in $\sigma_{x x}$ direction with different coverage rates and different shot velocities (a) $50 \mathrm{~m} / \mathrm{s}$; (b) $100 \mathrm{~m} / \mathrm{s}$

Fig. 5 Computed residual stress distribution in $\sigma_{x x}$ direction after SP with different coverage rates: (a) 100\%; (b) 200\%; (c) 300\%

Fig. 6 SEM image of reinforcements in the surface of $8 \%(\mathrm{TiB}+\mathrm{TiC}) / \mathrm{Ti}-\mathrm{Al}-4 \mathrm{~V}$ after etching.

Fig. 7 3D SP model for inhomogeneous materials

Fig. 8 Computed residual stress distribution in $\sigma_{x x}$ direction obtained from the inhomogeneous SP model

Fig. 9 Measured CRS distribution of Ti-6Al-4V under three different SP intensities $\left(\sigma_{x x}\right.$ direction $)$

Fig. 10 Measured CRS distribution of $8 \%(\mathrm{TiB}+\mathrm{TiC}) / \mathrm{Ti}-6 \mathrm{Al}-4 \mathrm{~V}$ under three different SP intensities $\left(\sigma_{x x}\right.$ direction $)$ 


\section{Table caption}

Table 1 Typical mechanical parameters of shot balls, targets and reinforcements 


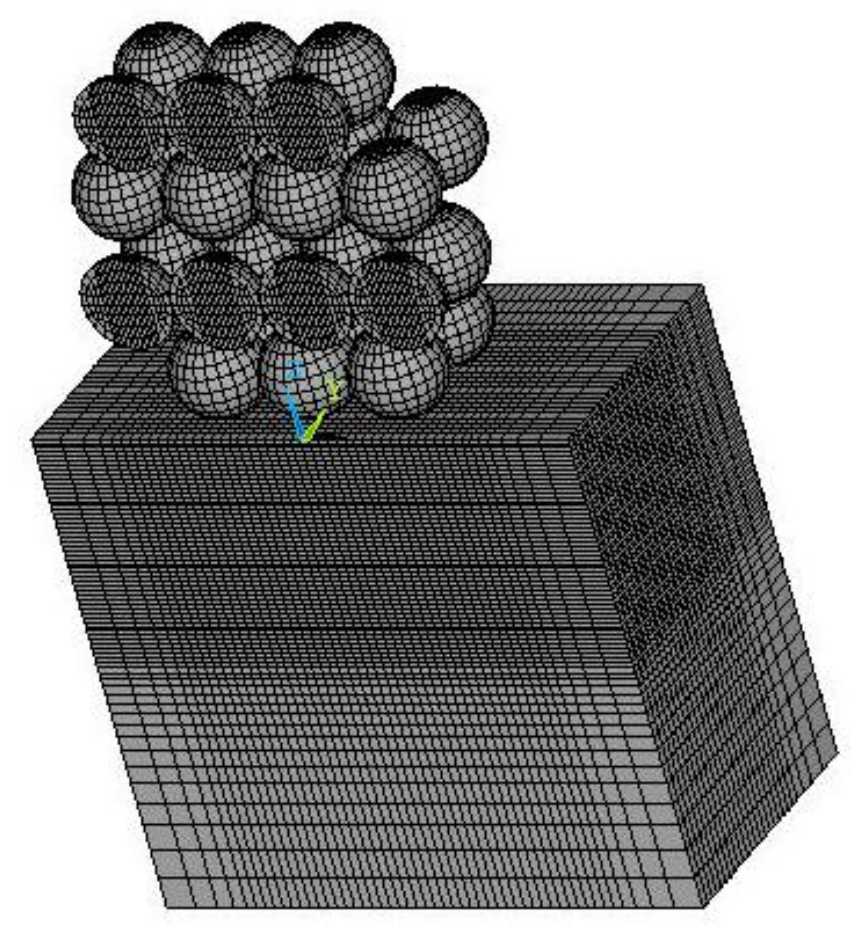




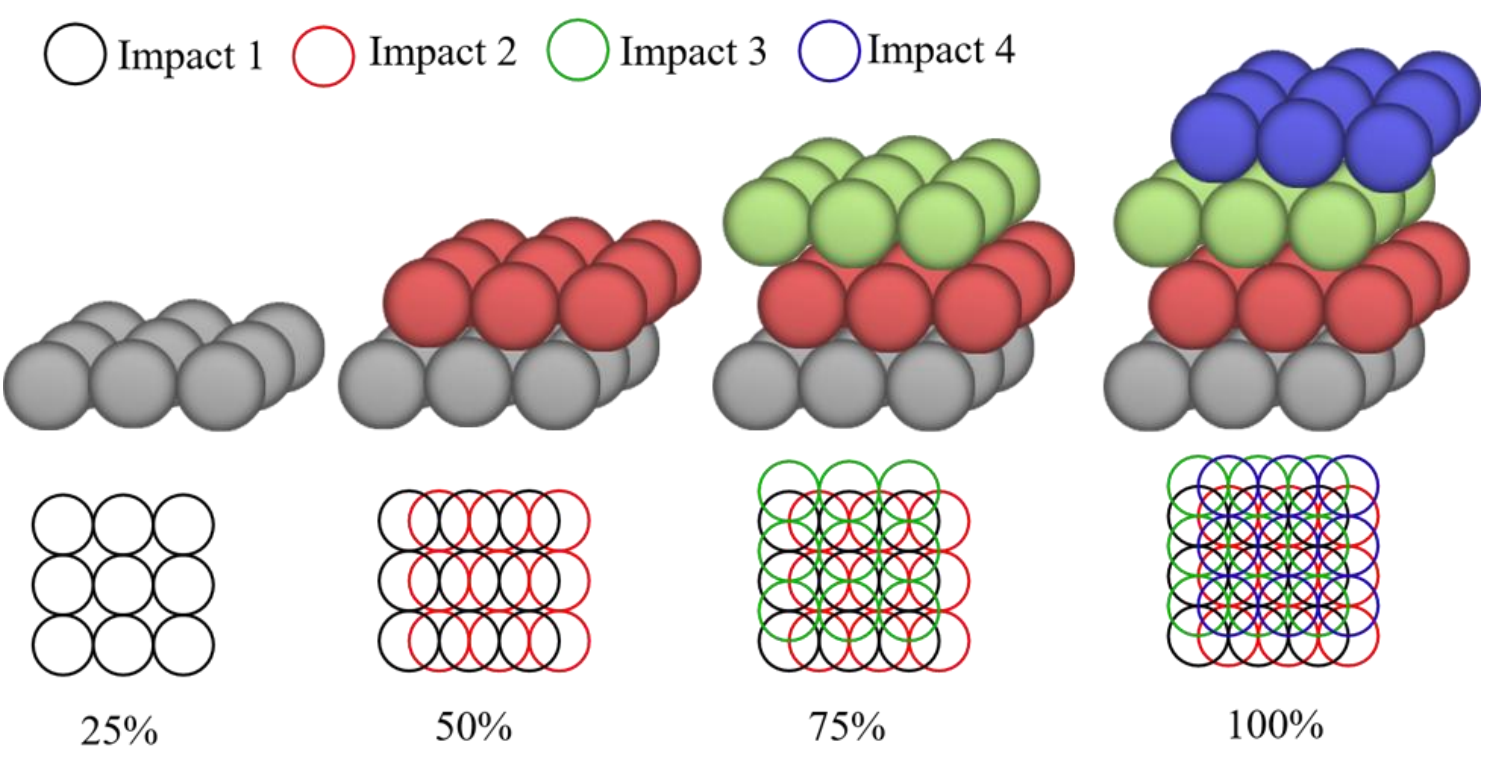




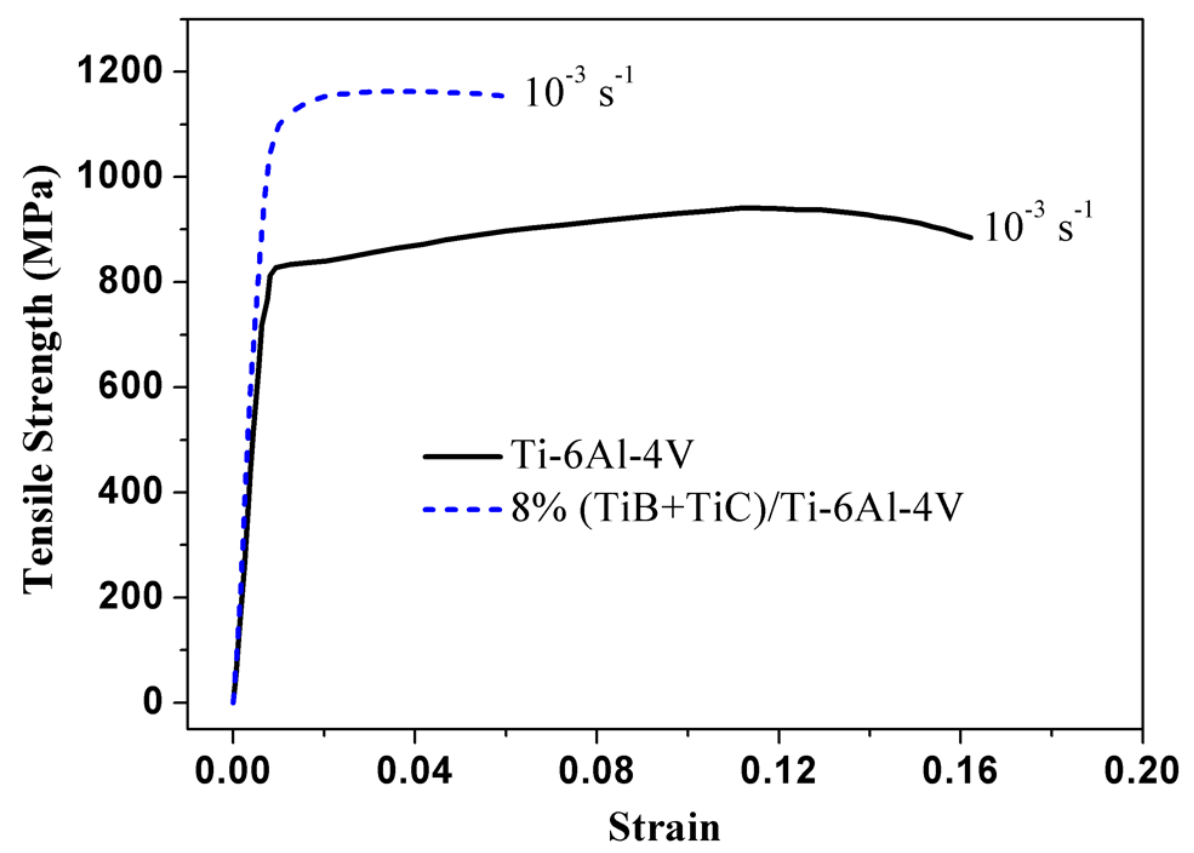



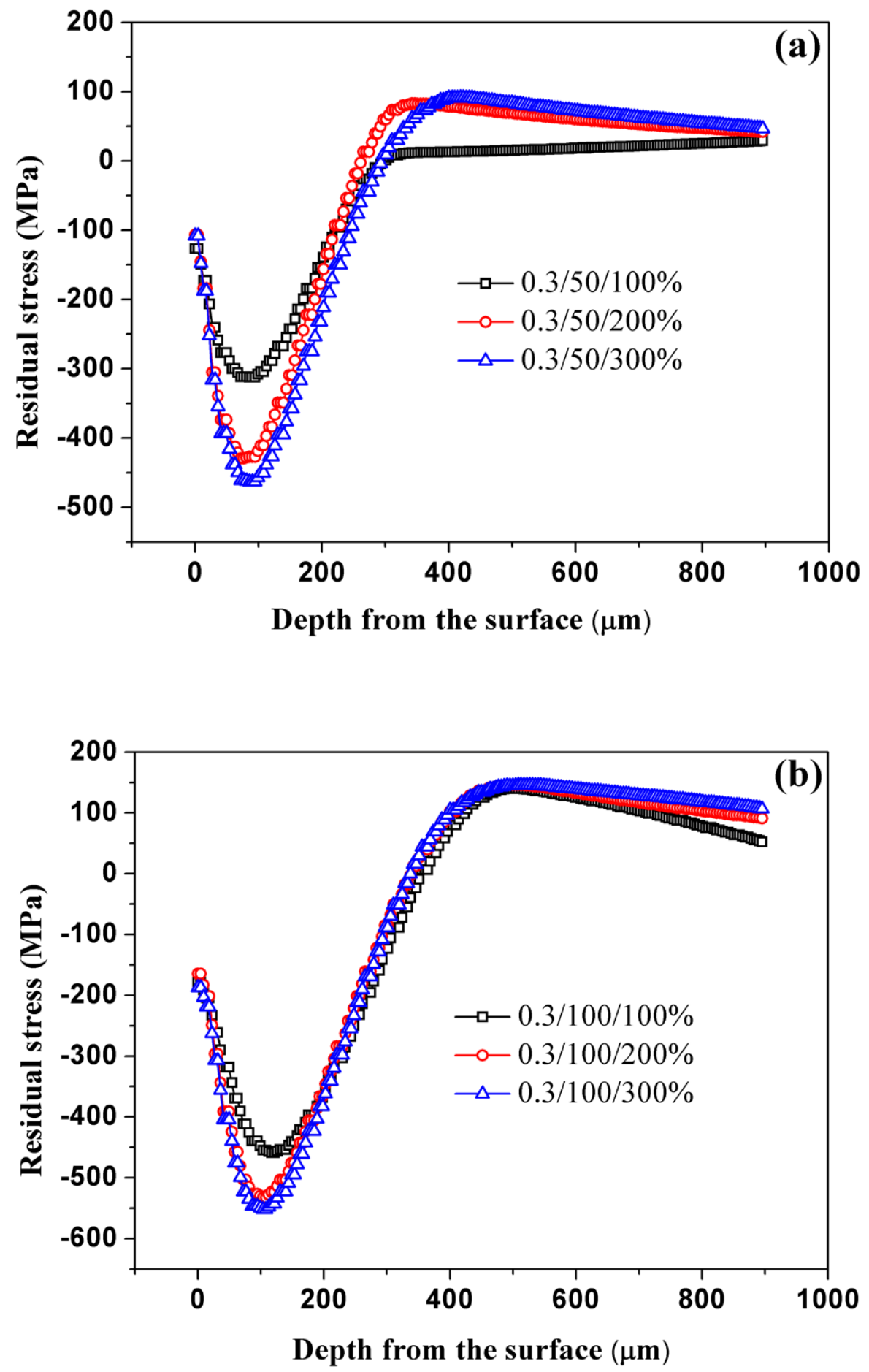


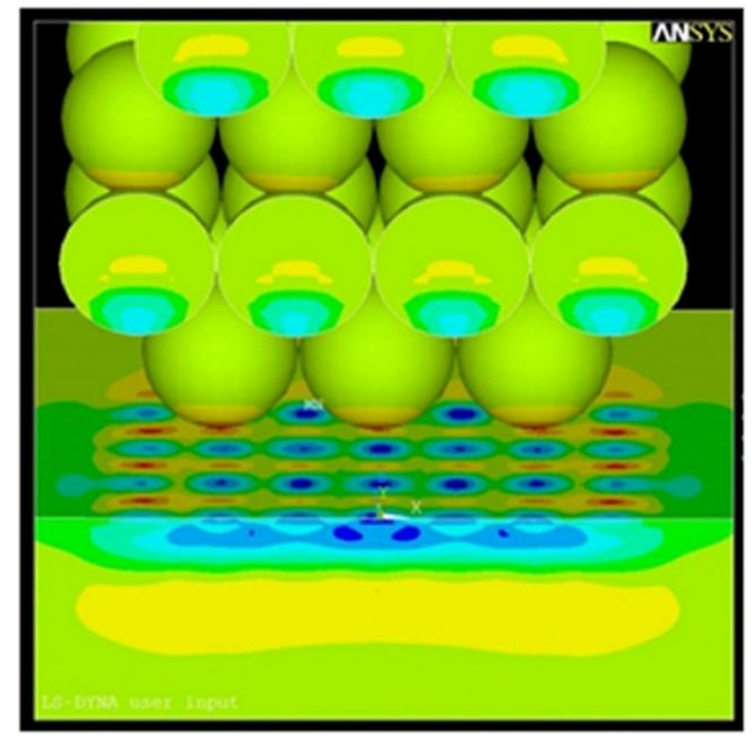

(a)

$100 \%$

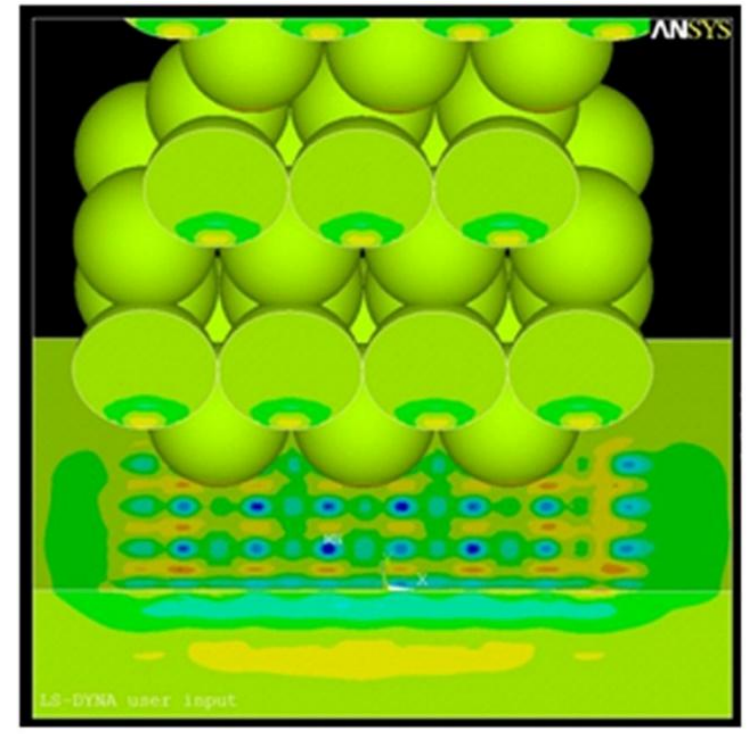

(b) $200 \%$
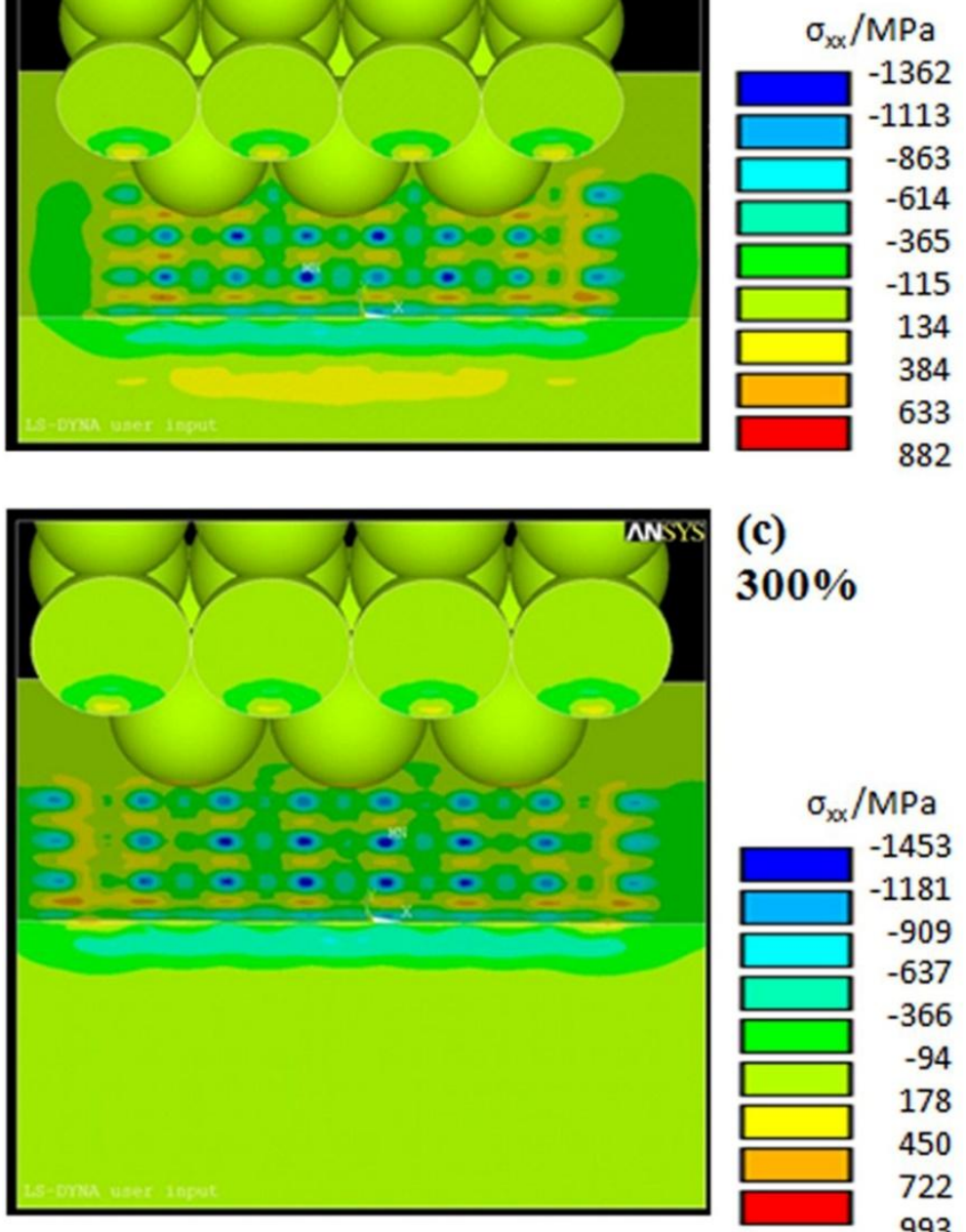

(c) 300\%

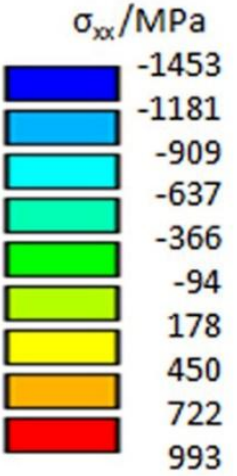




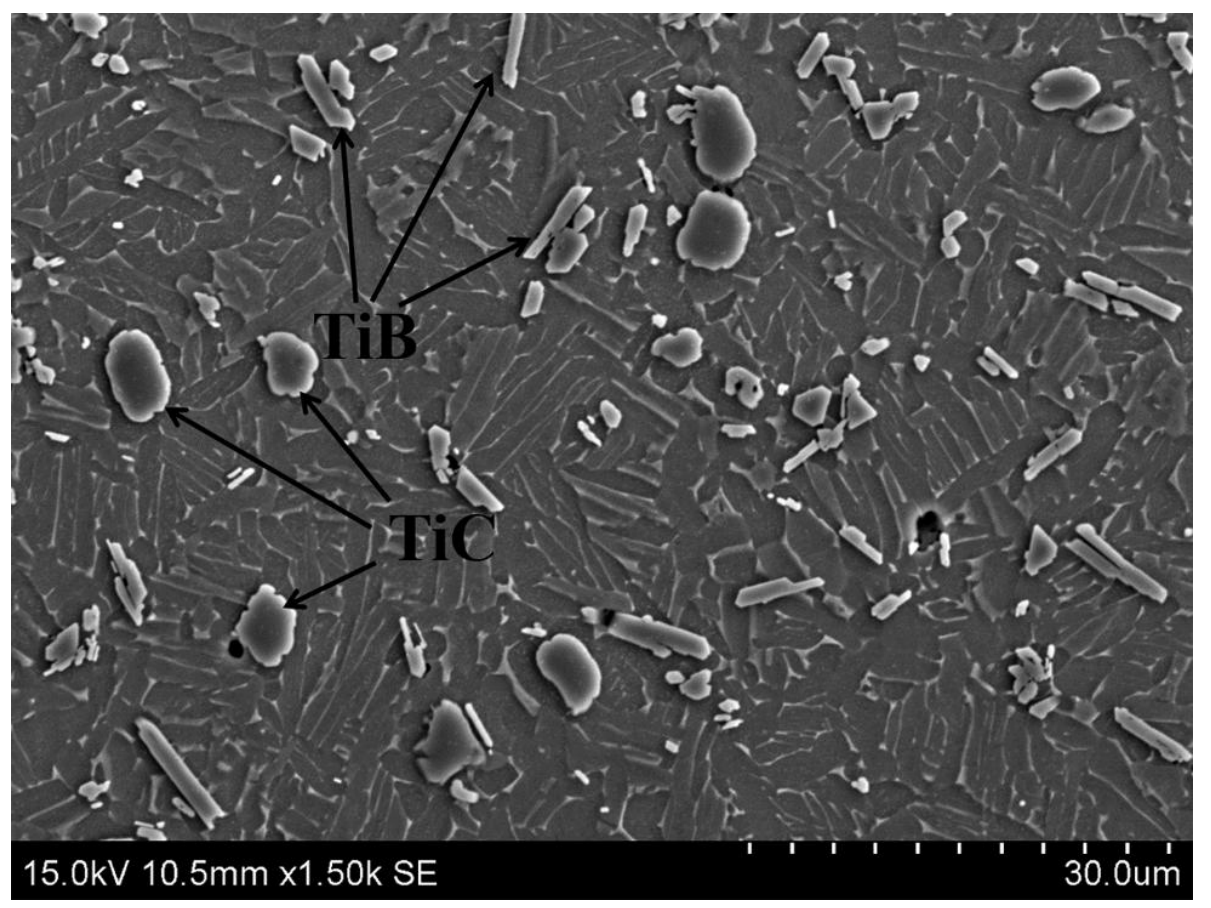




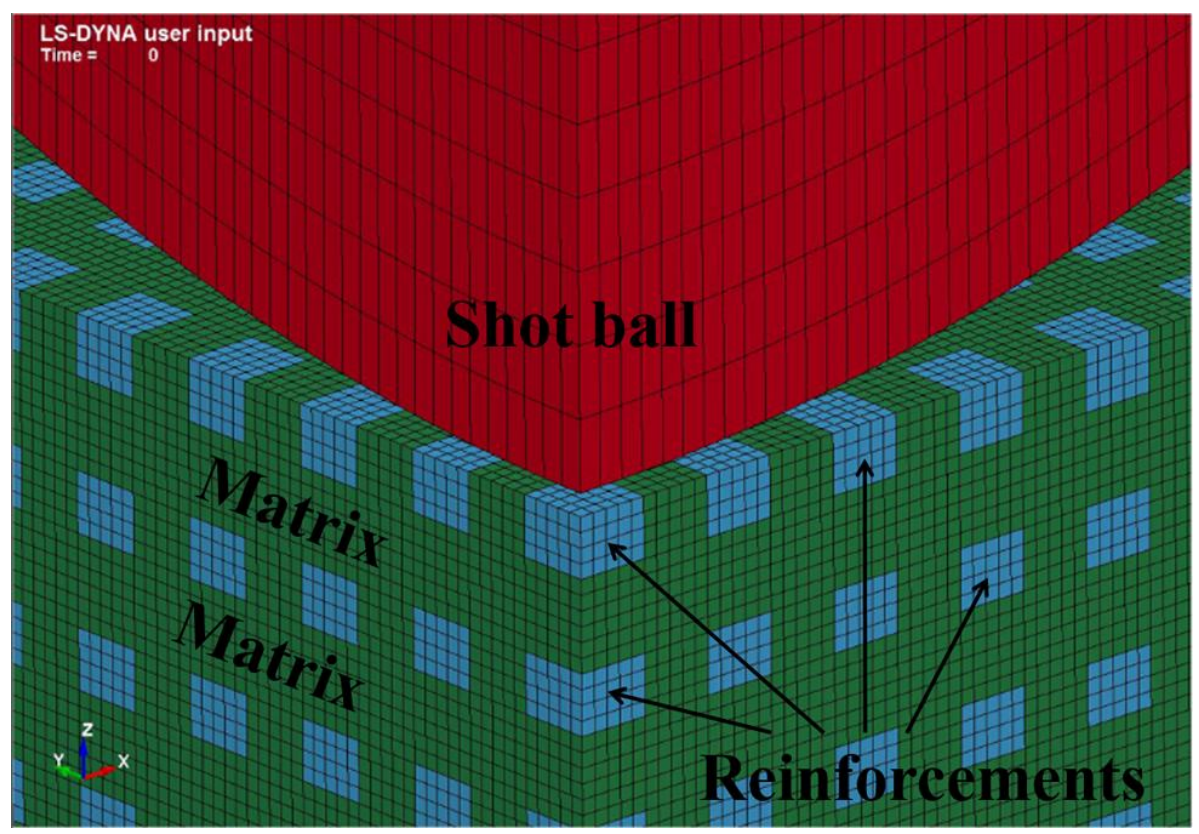




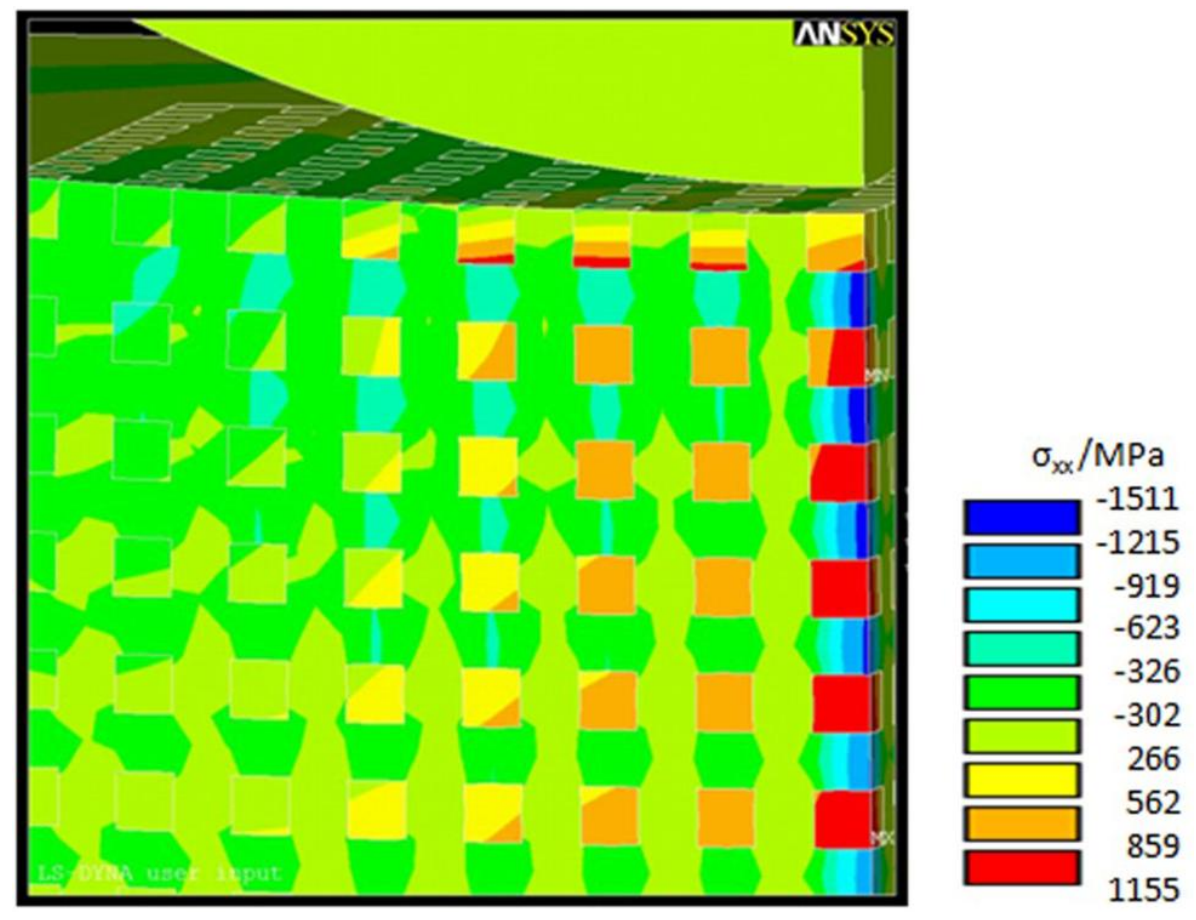




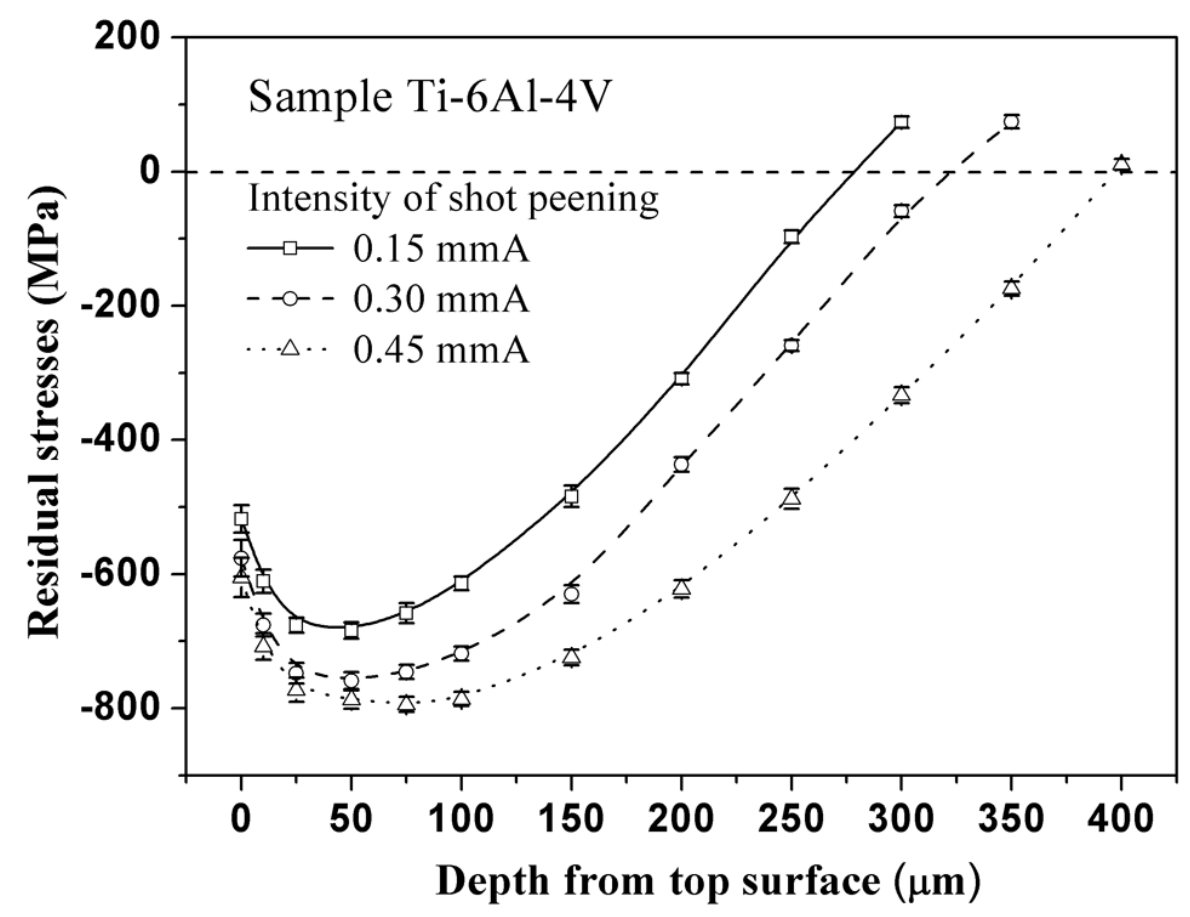




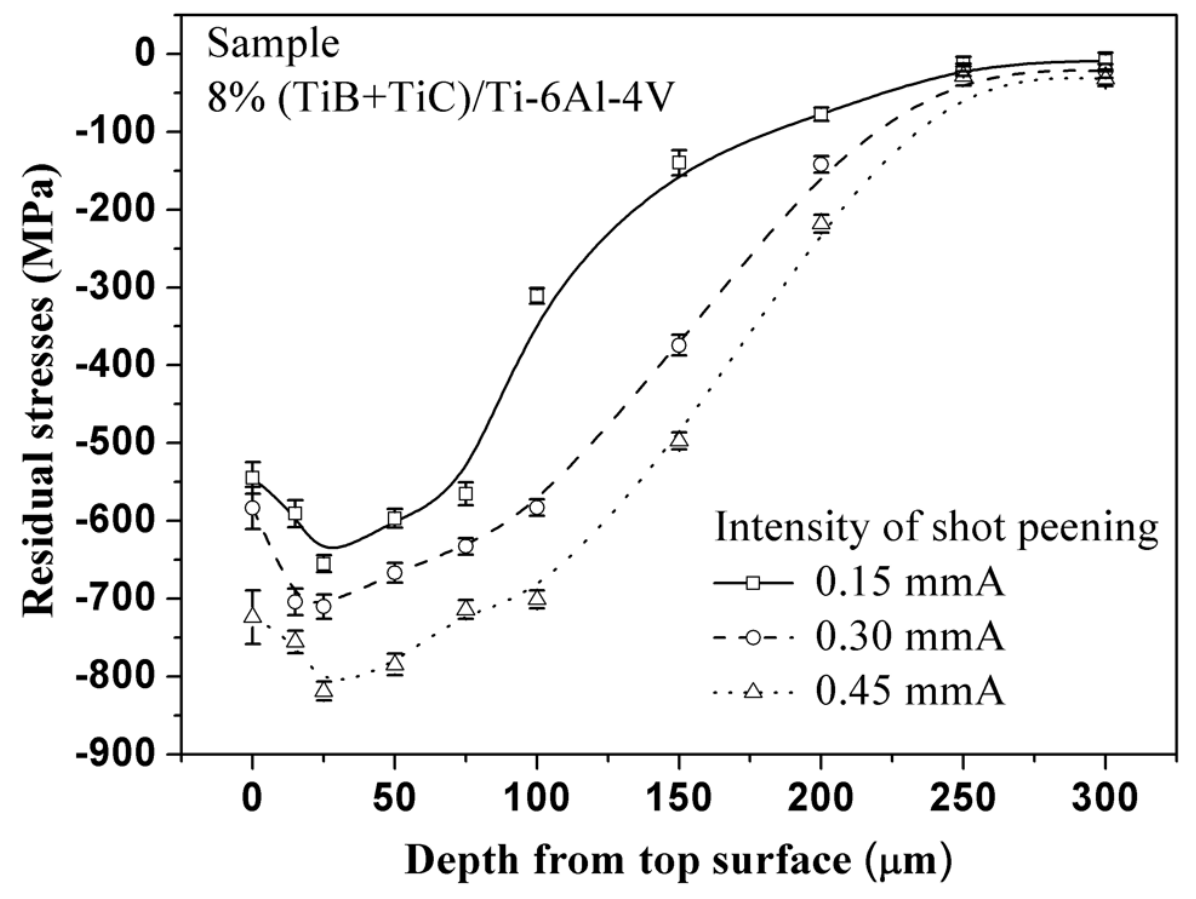




\section{Table 1}

Table 1 Typical mechanical parameters of shot balls, targets and reinforcements

\begin{tabular}{cccccc}
\hline & Shot balls & Ti-6Al-4V & TiB & TiC & (TiB+TiC)/Ti-6Al-4V \\
\hline Density $\rho\left({\left.\mathrm{Kg} \cdot \mathrm{m}^{-3}\right)}^{7}\right.$ & 7800 & 4500 & 4520 & 4930 & 4500 \\
Poisson's ratio v & 0.30 & 0.34 & $0.14-0.15$ & $0.18-0.2$ & 0.34 \\
Young's modulus $E(\mathrm{GPa})$ & 210 & 112 & $371-485$ & $400-460$ & 134 \\
Constraint of the part & Rigid & Elastic-plastic & Rigid & Rigid & Elastic-plastic \\
\hline
\end{tabular}

